\title{
Conceptual Models for Marine and Freshwater Systems in Alaska: Flexible Tools for Research Planning, Prioritization and Communication
}

\author{
Suresh Andrew Sethi ${ }^{1}$ and Tuula Hollmen ${ }^{2}$
}

(Received 2 December 2014; accepted in revised form 1 May 2015)

\begin{abstract}
Conceptual ecological models synthesize information about complex systems into simplified visual maps and can be used to prioritize system components for research or management attention. In this article, we introduce conceptual modeling methods that incorporate expert ratings about a suite of properties of system components, including assessment of the state of knowledge, the strength of ecological impact, and the state of management or research attention devoted to a given component. Quantitative ratings of the properties of system components are subsequently used to prioritize model components objectively for research or management attention. Two case studies, one on plankton-herring-baleen whale dynamics and one on Chinook salmon strategic research planning, are presented to illustrate techniques. For example, in the Chinook salmon case study, participants constructed a prioritization score that identified system components rated as high ecological impact, but low state of knowledge and low state of management or research attention. By addressing gaps in both knowledge and attention, participants implemented a strategy for research planning that complemented existing Chinook salmon research and management in the study region. The case studies demonstrated that conceptual ecological models could be completed successfully with an economy of time. Conceptual modeling has been implemented across a range of disciplines and provides a useful tool that natural resource management and research groups can use to organize collaborative efforts and communicate research or management progress to stakeholders or funders.
\end{abstract}

Key words: baleen whales; Chinook salmon; ecological modeling; herring; strategic planning; systems models

RÉSUMÉ. La modélisation conceptuelle écologique fait la synthèse de l'information de systèmes complexes pour produire des cartes visuelles simplifiées et permet de prioriser les éléments du système à des fins de recherche et de gestion. Dans cet article, nous présentons des méthodes de modélisation conceptuelle écologique qui englobent les données des experts au sujet d'une suite de propriétés d'éléments du système, y compris l'évaluation de l'état des connaissances, la force des incidences écologiques et la valeur de l'attention de gestion ou de recherche consacrée à un élément donné. Les notations quantitatives des propriétés des éléments du système servent, par la suite, à prioriser les éléments du modèle de manière objective aux fins de recherche et de gestion. Deux études de cas, une sur la dynamique du plancton, du hareng et du cétacé à fanons et l'autre sur la planification stratégique de la recherche sur le saumon quinnat, sont présentées pour illustrer les techniques. Par exemple, dans l'étude de cas sur le saumon quinnat, les participants ont établi une note de priorisation selon laquelle les éléments du système sont considérés comme ayant une incidence écologique élevée, mais un faible état des connaissances et de l'attention de gestion ou de recherche. En comblant les écarts en matière de connaissances et d'attention, les participants ont mis en œuvre une stratégie pour la planification de la recherche qui s'est greffée à la gestion et la recherche en cours sur le saumon quinnat dans la région à l'étude. Les études de cas ont démontré que la modélisation écologique pourrait être réalisée avec succès en moins de temps. La modélisation conceptuelle a été mise en place dans un large éventail de disciplines et offre un outil pratique que les groupes de gestion et de recherche des ressources naturelles peuvent utiliser pour organiser des interventions communes et communiquer les progrès de la recherche ou de la gestion aux intervenants ou fournisseurs de fonds.

Mots clés : cétacés à fanons; saumon quinnat; modélisation écologique; hareng; planification stratégique; modèles de systèmes

Traduit pour la revue Arctic par Nicole Giguère.

\section{INTRODUCTION}

Recognizing the importance of interdependencies in socioecological systems, policy makers and scientists continue to move toward ecosystem approaches to natural resource management (Christensen et al., 1996; Botsford et al., 1997;
MEA, 2005). Yet, even relatively simple systems like sea otters-urchins-kelp (Estes and Duggins, 1995) or singlespecies commercial fishing fleets (Branch et al., 2006; Fulton et al., 2011a) have proved challenging to understand. Furthermore, ecosystem-level management requires coordination across disciplines (e.g., between economists and

\footnotetext{
${ }^{1}$ Corresponding author: Fisheries and Ecological Services, U.S. Fish and Wildlife Service, 1011 E. Tudor Road, MS 331, Anchorage, Alaska 99503, USA; suresh_sethi@fws.gov

${ }^{2}$ Alaska SeaLife Center and University of Alaska Fairbanks, PO Box 1329, Seward, Alaska 99664, USA

(C) The Arctic Institute of North America
} 
biologists) and across stakeholder groups such as resource users and regulatory agencies. In this article, we demonstrate the use of conceptual models as a pragmatic tool to synthesize extant information about complex systems, communicate ideas to stakeholders and experts, and prioritize system components for strategic research or management planning. We introduce a conceptual modeling process that includes ways to generate quantitative ratings for a suite of properties of model components (such as the strength of ecological interactions and the state of knowledge about model components) using expert opinion. We demonstrate this process with two case studies related to aquatic and marine natural resource systems in which we discuss how the modeling process informs strategic research planning. Coupled with their relative simplicity to develop and implement, conceptual models provide a flexible tool for making informed decisions about how best to use limited time and financial resources to study or manage a socioecological system by focusing efforts on high-priority system components.

Systems models have played a critical role in understanding the dynamics of ecosystems. They span a gradient from purely qualitative conceptual models to fully quantitative end-to-end models (e.g., Ecopath: Pauly et al., 2000; Atlantis: Fulton et al., 2011b; also see Rose et al., 2010). Fully quantitative system models are challenging to implement and can suffer from high data requirements to parameterize simulation models (Marcot et al., 2006; Uusitalo, 2007; Fulton et al., 2011b). But conclusions about such implementations stress the benefit of the development process: existing knowledge about complex systems is synthesized, communication is facilitated across disciplines and between stakeholders involved in model interpretation, and information or management gaps are identified (Marcot et al., 2001; Zorrilla et al., 2010). Many of these benefits are also achievable with qualitative conceptual models, and depending on modeling objectives, a simplified approach may be an adequate and time-efficient way to move forward. Conceptual models extract diffuse information from experts or the literature and synthesize understanding of complex systems into tractable conceptual maps (Howard, 1989). They can be used to identify knowledge or management gaps (see below) and can also serve as a framework for conducting structured thought exercises or simple management simulations (Radomski and Goeman, 1996). Indeed, conceptual model development is often an initial step in designing quantitative systems models, providing a schematic for subsequent simulation model construction and highlighting key components to capture when simulating or designing management actions. While quantitative system models are important tools for designing specific management actions for ecosystems, such as harvest schedules or the placement and design of area closure networks, conceptual models allow for complex system representation without the explicit need for mathematical models or even quantitative data, if expert opinion is available to inform models. In other words, what conceptual models lack in mathematical rigor, they compensate for in their simplicity to develop and their practical usefulness for strategic research planning and synthesis of systems understanding.

Conceptual modeling exercises to synthesize information and visualize the structure of complex systems can be found across a wide range of disciplines-from operations research (Robinson et al., 2010) to education (Novak and Cañas, 2006) to ecosystem-based management (Harwell et al., 1996; Ogden et al., 2005 and related articles in the special issue of Wetlands, Vol. 25; King and Hobbs, 2006). In addition, conceptual models provide valuable support tools for structured decision analysis and have been widely used in that context (e.g., Conroy and Peterson, 2013). The conceptual modeling techniques we focus on in this paper are those that we have found to be both flexible and useful for strategic research planning. They are most closely related to conceptual modeling as employed in operations research (Robinson, 2008a, b) and similar to the cognitive mapping approach (Axelrod, 1976; Kosko, 1986) originally developed in political science. However, we do not implement a formal fuzzy logic approach (e.g., Özesmi and Özesmi, 2004) to synthesize model input, finding this to be unnecessary to achieve the objectives of many conceptual modeling exercises. Likewise, mental model applications in environmental science implement a similar process to elicit stakeholder beliefs about system attributes and highlight key model components, information gaps, and management priorities (e.g., Bostrom et al., 1992; Zaksek and Arvai, 2004).

Conceptual models take on a range of forms, depending on the application; however, they share commonalities. First, conceptual modeling exercises begin with formulation of the objectives to be achieved. Examples include:

- Research groups: identify high priority research areas for subsequent study; or, provide a working hypothesis of a complex socioecological system with which to communicate research efforts to the public and to funders, and track learning about the system as a result of research efforts.

- Natural resource management agencies: maximize conservation benefit from limited restoration funds by focusing efforts on critical system linkages; or, improve complementarity with other management agencies sharing jurisdiction over a socioecological system by identifying management gaps.

Second, existing information-be it from empirical data, published literature, or expert opinion-is synthesized into a set of system components. Third, interdependencies, or linkages, in the system are identified. Fourth (optional step), expert- or literature-derived assessments of attributes of system component or linkages are input into the model. Fifth, a visual representation of the structure of the system is constructed. Finally, results of the modeling exercise are disseminated among stakeholders and conclusions are discussed. The process is typically collaborative and iterative.

Below we outline a flexible process for implementing conceptual ecological models that incorporate expert input. 
Instead of aiming to forecast system outcomes, we suggest that such modeling can synthesize understanding of a system, identify gaps in knowledge or management for strategic planning, and, if repeated over time, track the state of learning as research results inform system understanding. Techniques are demonstrated with two examples from Alaska, one on Pacific herring (Clupea pallasii)-baleen whale dynamics and one on strategic research planning for Chinook salmon (Oncorhynchus tshawytscha). Using ratings from experts to inform models, groups were able to prioritize areas of high ecological importance about which relatively little is known or which receive little management attention, providing a transparent and objective method for strategic planning.

\section{METHODS}

Our approach to the conceptual modeling process to synthesize knowledge and prioritize system components for research or management attention has followed a regular sequence of steps (also see Suter, 1996; Gross, 2003): i) define objectives of the modeling exercise and organize relevant modeling participants, ii) determine the set of components to include in the model, iii) define linkages among model components, iv) score attributes of model components that are relevant to the modeling objectives and, if desired, generate prioritization ratings, and v) visualize results and communicate outcomes. Conceptual ecological models can be informed by scientific literature (e.g., Simenstad et al., 2006), expert opinion (e.g., Radomski and Goeman, 1996), or some combination thereof (e.g., Harwell et al., 2010; see below). Whether organizing a literature review or garnering expert input to inform a conceptual model, the project will require one or more core facilitators to move the process along. Here we focus on efforts to inform conceptual ecological models through a combination of literature and expert opinion: model facilitators use their existing knowledge base and relevant literature to propose an initial conceptual model structure, which is then refined with expert opinion. The model development material discussed below, such as protocols to reach consensus about final models, also applies to models informed purely by literature.

\section{Define Objectives and Organize Participants}

We begin conceptual model development by identifying the objectives for conducting a modeling exercise, typically with the goal of writing down a concise statement that summarizes the desired outcome(s) of the model development process. For example, the objectives of the zooplankton-herring-whale modeling exercise were to synthesize understanding about the key processes affecting Pacific herring-baleen whale foraging dynamics and to refine a rating system for quantifying expert opinion about the properties of linkages in northern Gulf of Alaska ecosystems in a group of principal investigators involved in a large-scale monitoring project (Gulf Watch Alaska project; www.gulfwatch.org). In the Chinook salmon modeling case study, the objective was to synthesize current understanding of the Chinook salmon life cycle and the associated stressors affecting survival through life stages in order to identify knowledge and management gaps in the southcentral and western regions of Alaska. Once identified, knowledge and management gaps would then be used to prioritize future research efforts.

After identifying the objectives of the exercise, we organize a set of expert participants from whom to seek input into a conceptual model. In many cases, the universe of participants derives directly from the objectives of the modeling exercise. For example, in the Chinook salmon case study, the objective involved strategic planning for a management agency (U.S. Fish and Wildlife Service), and thus the universe of participants was constrained to agency staff. In the zooplankton-herring-whale case study, the express purpose of the exercise was to synthesize the system dynamics knowledge of the Gulf Watch Alaska program principal investigators. Depending on the objectives of the exercise, participants may have similar expertise (e.g., salmon ecology), or the process may be designed to have a balance of expertise when working with ecosystemlevel models (e.g., models of intertidal ecology or physical oceanography). More formally, experts could be asked to rate their ability to contribute to parts of a conceptual model, and consensus models could summarize this information throughout different components of the final model (e.g., McDaniels et al., 2010), for example, by presenting linkage rating values weighted by experts' self-rating scores (or ratings based upon a set of calibration questions; cf., Wittmann et al., 2015).

Some conceptual ecological modeling efforts, particularly those involving resource allocation, encompass diverse stakeholders with potentially conflicting interests. Modeling participants may bring perspectives about the modeled system specific to their experience, knowledge base, or special interest agenda. In such cases, obtaining a diverse set of participants with representation from the set of stakeholder groups encompassed by the objectives of the modeling exercise may help balance individual-specific biases to produce a group consensus model that adequately represents the system as a whole (e.g., Hastie and Kameda, 2005; but see Kerr et al., 1996). In other situations, it may be possible to census all stakeholders encompassed by a modeling process - a scenario similar to the Chinook salmon research planning modeling effort for a single management agency, as detailed below. Finally, participants with experience in conceptual modeling can improve the efficiency of the process. Similarly, avoiding people whose personalities can disrupt the process or who actively seek to prevent progress in a modeling effort is of practical importance, particularly when a modeling effort is centered around contentious resource systems with opposing stakeholder interests. 


\section{Define Model Structure and Score Attributes}

After the participant pool has been organized, we propose a starting conceptual model informed by the appropriate scientific literature, presenting the group with a "prior" model to be updated by participants' input. The structure of the starting model matches the modeling exercise objectives. For example, in the Chinook salmon case study, the objective of the modeling exercise was to identify and prioritize research efforts for key stressors on juvenile Chinook salmon; thus, the conceptual model contained life stages and stressors. In other modeling exercises, such as the herring-whale modeling case study presented below, the focus may be on understanding the structure of the system. In these applications, models focus on ecosystem components as opposed to anthropogenic stressors. While providing participants with a prior model is not a necessary step, we have found that presenting respondents a framework from which to build facilitates group input, as opposed to starting from scratch and dealing with group unwillingness to participate or paralysis faced with the complexity of writing down a model in a short time. Furthermore, by preparing a prior model, facilitators can draw from the extant literature at the time of the exercise (e.g., Cormier et al., 2009).

Next, we incorporate participants' input to update the model structure. In this step, respondents are asked to decide which components of a conceptual ecological model should be retained, discarded, or added. Then, to represent interactions in the conceptual model, the respondents are asked to define linkages between model components, and optionally, to rate properties of the linkages using a series of questions related to the objectives of the exercise. For example, in the Chinook salmon case study, we asked respondents to rate linkages between stressors and Chinook salmon life stages in terms of severity of impact, state of knowledge about the impact, and state of research or management attention currently being devoted to the stressor and its impact on a given life stage. For the herring-whale model, we asked respondents to rate a suite of properties of linkages among ecosystem components, including strength of interaction, variability of interaction, and spatiotemporal scales. We also asked respondents to rate the current state of knowledge about linkages to facilitate further analysis of research priorities for the program.

Participants could conduct modeling exercises as a group and collaboratively discuss decisions to include or discard model components or linkages, or alternatively, these exercises could be conducted individually. Both approaches have benefits and weaknesses. Modeling exercises conducted as a group facilitate flow of information and spur creativity, benefiting brainstorming and problem solving (e.g., Hill, 1982); however, they can result in "group think," whereby group responses gravitate toward the more vocal participants or majority points of view, potentially reducing the diversity of information input into conceptual models (Maier, 1967; Schmoldt and Peterson, 2000). Individually completed modeling exercises reduce the time necessary to keep a group of participants together and, if assigned as a task to be completed at a later date, allow participants ample time to reflect on their responses or consult literature. We caution, however, that facilitators will have limited ability to provide clarification on the conceptual modeling or ratings process if modeling exercises are assigned as a task to be completed at a later date. Furthermore, significant follow-up communication may be required to ensure that all participants successfully complete the responses.

Regardless of the method of conducting and recording input, the next step is to generate a consensus model based upon participants' responses. Consensus on model components and linkages can be achieved using a majority rule (e.g., retain a component if $50 \%$ or more of the respondents included it) or a threshold rule (e.g., include a component if at least three respondents included it). Linkage ratings can be summarized using descriptive statistics such as means or medians. Furthermore, the degree of consensus on a linkage rating can be summarized by examining the variability in rating responses; low variability suggests agreement (and high variability, disagreement) within the group. For transparency, when presenting results from a conceptual modeling exercise, we recommend including information about the expertise of modeling participants, as well as information on the degree of consensus among participants for final consensus models.

\section{Prioritize Scores}

In addition to synthesizing existing information about a modeled ecosystem, an important practical use of conceptual ecological models is to prioritize system components for follow-up study to fill knowledge gaps or to identify high-priority components in need of management attention. Expert ratings of model components or linkages can be used to generate numerical prioritization scores that address modeling objectives related to strategic research and management planning. A ratio score that takes the strength of interaction over the state of knowledge is useful for highlighting system linkages that are ecologically important and which are poorly understood. An alternative approach is to construct an additive score that incorporates multiple factors in a prioritization effort, such as consideration for the strength of a given interaction, the state of knowledge about the interaction, and the state of attention devoted to managing or understanding the interaction. With composite scores, modelers can either implement equal weighting of the prioritization factors or assert different weights for different factors. An advantage of generating numerical scores is that the process of prioritizing model components or linkages for research or management attention can be made transparent, clearly communicating the rationale for planning decisions. Furthermore, numerical scores enable comparison of differences in prioritization emphasis across groups of scorers. For example, prioritization scoring for a given conceptual model could be carried out separately with focus groups-such as regulators, user 
groups, or scientists in a natural resource management system - so that a comparison of scores could be used to highlight commonalities and differences among stakeholder groups in the perceived importance of system components (e.g., Zaksek and Arvai, 2004).

\section{Visualize and Communicate Results}

The final consensus model represents the prior model updated by expert opinion. The last step in the process is then to communicate the results to the group of respondents and other interested parties to achieve the objectives outlined in the first step. A visual representation of the final consensus model presents a succinct working hypothesis of the modeled system and serves as a tool to communicate beliefs about the structure of a system across stakeholders. If model components were scored as part of the effort, the conceptual model visualization can be augmented with tables or figures that summarize model ratings scores. The conceptual modeling development process and the communication of results can be repeated iteratively, for example, to examine whether system understanding has changed as a result of research and management efforts over time. They could also be conducted with multiple groups independently, for example, if logistical constraints prevented gathering modeling participants together at the same place and time, and then results could be merged into an updated consensus model.

\section{Case Study 1: A Zooplankton-Herring-Whale Model}

This modeling exercise was conducted over one day at a November 2012 meeting of principal investigators for the Gulf Watch Alaska project, a multidisciplinary project funded by the Exxon Valdez Oil Spill Trustee Council to address long-term changes in the northern Gulf of Alaska. The objectives of the zooplankton-herring-whale modeling exercise were to synthesize current understanding about the key processes affecting Pacific herring-baleen whale dynamics in Prince William Sound, Alaska, identify linkages in the system, and refine a linkage rating system to quantify expert opinion, in order to facilitate strategic planning among the investigators involved in the long-term monitoring program. The group of modeling participants consisted of 19 investigators familiar with Gulf of Alaska ecosystems and with expertise balanced among marine ecology $(n=7)$, physical and biological oceanography $(n=6)$, and wildlife biology $(n=6)$. The exercise was facilitated by the authors, who also provided model responses. This conceptual modeling exercise focused on one subsystem within the Gulf of Alaska ecosystem, herring and baleen whales, and was undertaken to train experts for a later broader conceptual modeling exercise with the goal of developing a parsimonious conceptual model to describe the key ecosystem processes for the northern Gulf of Alaska (see www.gulfwatchalaska.org for additional details).
Respondents were provided with a "prior" zooplankton-herring-whale system model and asked first to draw in relevant linkages and then to rate properties of linkages. Linkage rating questions examined whether a given linkage had a positive or negative impact from the upstream to the downstream component, the strength of the linkage, the degree of stability of the linkage, the temporal and spatial scales at which a linkage operates, and the state of knowledge about the linkage (online Appendix 1; the prior model handout provided to the group is available from the authors upon request). Respondents indicated ratings on a scale of 1 to 5 and completed individual questionnaire worksheets. The scale of 1 to 5 was selected on the basis of pilot rating exercises with a three point, "high-medium-low" rating scale, in which a subset of modeling participants indicated a desire for additional categories.

After completion of the modeling session, linkagerating data were processed in the $\mathrm{R}$ statistical programming environment (R Development Core Team, 2013), accounting for both the directions of linkages and values for linkage ratings questions (example data matrices available from the authors upon request). We used a simple majority rule to determine whether a linkage should be retained in a final consensus model, retaining any linkage included by $50 \%$ or more of the respondents. A consensus threshold of $75 \%$ was also tested; however, the group of experts had a high degree of agreement on the existence of linkages, and the set of linkages remained unchanged. We used the mean linkage rating value among those respondents who included a retained linkage to reflect a consensus rating, and we assessed group agreement by calculating the standard deviation of the numerical expert ratings for a retained linkage. To prioritize areas for future research attention, we calculated the ratio of mean strength of interaction response to mean state of knowledge response for each linkage. Linkages with high scores indicate high strength of interaction but low current state of knowledge, which makes them high-priority research targets. Finally, at the end of the modeling exercise, we asked the respondents to critique the linkage rating questions and suggest improvements.

\section{Case Study 2: Stressor-Impact Modeling of Chinook Salmon}

This modeling exercise, conducted in one day at the U.S. Fish and Wildlife Service field office in Kenai, Alaska in September 2013, was an assessment of risks to Chinook salmon undertaken to help the group prioritize research and management efforts for Chinook salmon in southcentral and western Alaska (cf. U.S. EPA, 1992). The objectives were to identify the key Chinook salmon life history stages, identify key stressors affecting survival through each life stage, and finally rate the stressor impacts at each life stage in terms of the strength of the impact, the state of knowledge about the stressor and its impact, and the state of management and research attention being provided to the stressor and its impact by the U.S. Fish and Wildlife Service or other organizations (e.g., State of Alaska 
management agencies, academic institutions, and nonprofit research groups). The group of modeling participants consisted of 10 investigators from the U.S. Fish and Wildlife Service with expertise in fisheries and aquatic ecology. The exercise was facilitated by one of the authors (S.A. Sethi), who also provided model responses. The consensus model including life stages and relevant stressors represented a working hypothesis for Chinook salmon in south-central and western Alaska, and stressor impact ratings were used to identify gaps in knowledge or management/research attention, providing a tool to help administration staff prioritize future research efforts.

Respondents were provided an initial set of Chinook salmon life stages drawn from the salmon ecology literature (cf. Groot et al., 1995; Spence et al., 1996), and the group collaboratively reasoned through the prior model to aggregate, disaggregate, retain, or discard life stages. Consensus was reached in a group discussion session, using a simple majority rule and verbal voting to set the list of agreedupon life stages. Next, respondents were provided an initial set of stressors, grouped into "environmental," "biological," and "anthropogenic" categories. Working from the prior list of stressors, a group discussion was undertaken to modify, add, or remove stressors, again using verbal voting and a majority rule to set the final list of stressors.

In the final step of the modeling exercise, respondents were given a worksheet with all possible stressor-life stage combinations and asked to rank the stressor impact according to three ratings attributes outlined above (for detailed results, see online Appendix 2). Stressors were rated on a 1 to 5 scale; respondents could indicate that a stressor was irrelevant at a given life stage by giving it a "1" for its impact rating. Ratings were processed in $\mathrm{R}$ using mean values to reflect consensus ratings and standard deviations to assess agreement within the group. To summarize consensus ratings for stressor-life stage ratings and separate out unimportant stressors, we used a threshold rule, retaining a given stressor-life stage combination if at least $50 \%$ of the group provided an impact rating greater than 1 . To prioritize future research efforts for Chinook salmon, we constructed a composite score that equally weighted the strength of impact, state of knowledge, and attention ratings for each retained stressor-life stage combination; stressors rated as high impact, poor state of knowledge, and garnering little research or management attention were ranked as high-priority areas for future work.

\section{RESULTS}

\section{Case Study 1: Zooplankton-Herring-Whale Model}

The consensus model contained eight linkages throughout the zooplankton-herring-whale model (Fig. 1). Overall, participants had the highest degree of consensus when rating the temporal and spatial scale at which linkages operate (Table 1) and the lowest when rating the strength of linkages.
The strongest linkages were the positive effect of zooplankton on herring (mean rating $=3.9$ out of 5.0), the positive effect of upwelling on zooplankton (mean rating $=3.6$ ), and the positive effect of herring on whales (mean rating $=3.5$; Fig. 1). Appendix 1 provides additional detail on the rating scales employed in this exercise; however, a strength of interaction rating of 3.0 indicates that a change in one component in a system results in a moderate change in the state of another component, but is not considered a main driver of that change, whereas a rating of 5.0 indicates that one component is a main driver of change in another component. Experts rated the effect of whales on zooplankton as the weakest linkage retained in the consensus model.

The most localized interactions in the consensus model were related to predation (Fig. 1), with these processes occurring at the scale of tens of kilometers (mean ratings from 2.4 to 3.2; online Appendix 1). The largest-scale processes involved the effect of ocean acidification on zooplankton (mean rating $=4.9$ ) and the effect of upwelling on ocean acidification (mean rating $=4.6$ ), which occurred at the scale of thousands of kilometers, i.e., basin-wide in the Gulf of Alaska (online Appendix 1). The range of experts' ratings of temporal scales was more compressed, with mean ratings across linkages of 1.8 to 3.4. The fastest interactions involved predation, occurring on a monthly or seasonal time scale, and the slowest interaction involved the effect of ocean acidification on zooplankton, occurring on a scale of years.

Respondents determined that linkages in the zooplankton-herring-whale model were similar in terms of the variability of the interaction between components, with mean ratings ranging from 2.6 to 3.5 (Fig. 1). A rating of 3.0 for this question indicates that an interaction has some predictability, but is inherently stochastic; a rating of 5.0 indicates that an interaction is direct and persistent, and a change in one element produces a predictable response from another element (rating of 5.0; online Appendix 1). The most stable interactions involved the upwelling-zooplankton-herring chain, whereas the most variable interactions involved the effect of whale predation on herring and zooplankton and the effect of upwelling on ocean acidification.

Finally, respondents rated the state of knowledge about the effect of ocean acidification on zooplankton to be the poorest, while the effect of zooplankton on herring was rated as the best understood linkage. However, the highest mean rating for any linkage was 3.5 , which indicates that although some empirical evidence exists to support a linkage, the evidence is not conclusive (online Appendix 1).

On the basis of the prioritization score, defined as the ratio of the consensus strength of interaction to the state-ofknowledge rating for linkages, interactions involving ocean acidification were rated as highest priority, followed by the effect of zooplankton on herring (Table 2). Although the latter linkage was rated as the best understood, it was also rated as a high-impact effect. Top-down effects of whale on zooplankton were rated as having a relatively lower priority in this system. 


\section{STRENGTH OF INTERACTION}

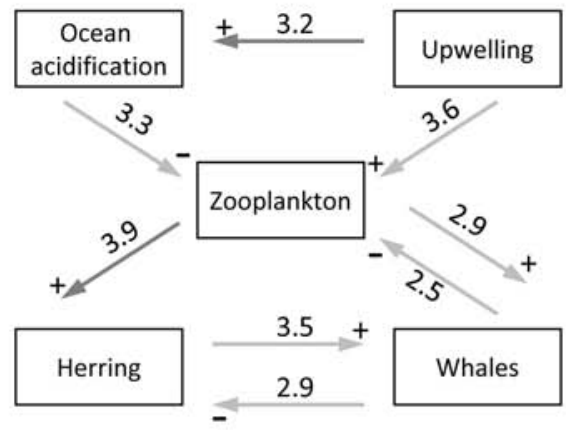

VARIABILITY OF LINKAGE

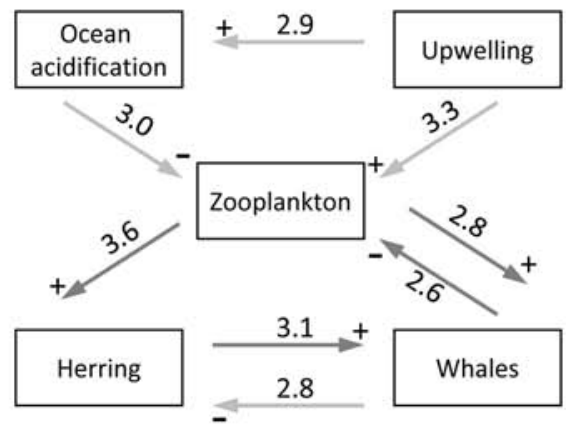

SPATIAL SCALE

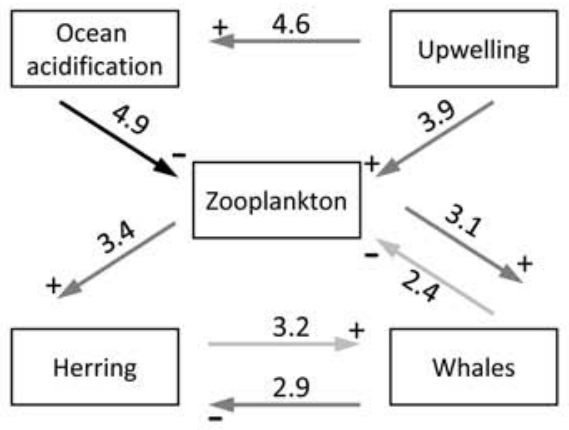

STATE OF KNOWLEDGE

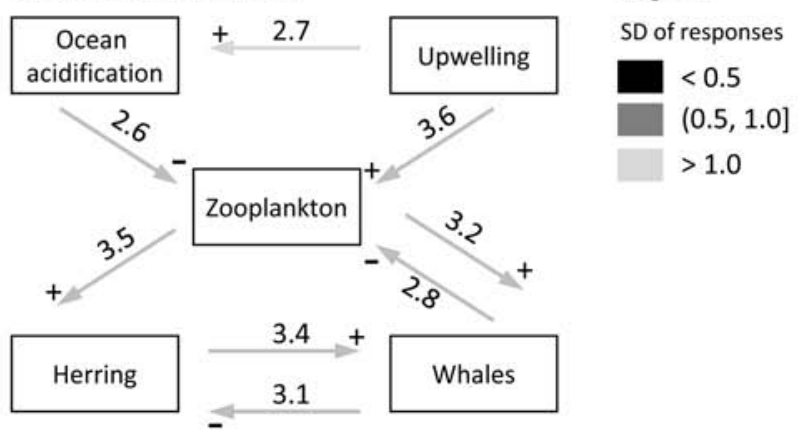

TEMPORAL SCALE

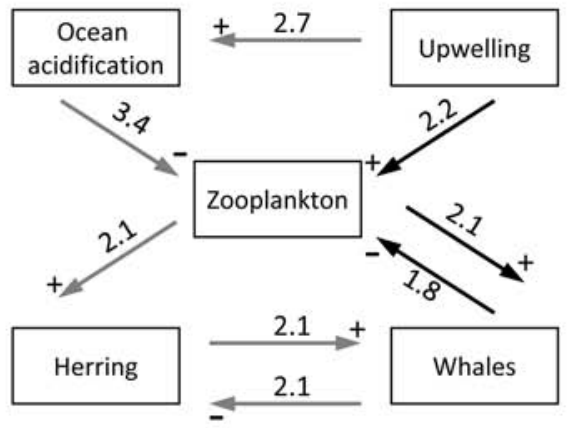

Legend

SD of responses

0.5

.5, 1.0]

FIG. 1. Consensus model results for the zooplankton-herring-whale model. A linkage of $X \rightarrow Y$ indicates that $X$ affects $Y$, and the direction of effect (+ for positive or - for negative) is indicated on linkage arrows. A given linkage was retained in the consensus model if $50 \%$ or more respondents included it. Numerical values from 1 to 5 represent mean ratings among participants who rated a given linkage (see online Appendix 1). Linkage arrow shading corresponds to the level of agreement by respondents about a given linkage rating as measured by the standard deviation of ratings, with darker shades indicating higher agreement.

TABLE 1. Assessment of the degree of consensus about linkage ratings for the zooplankton-herring-whale model.

\begin{tabular}{ll}
\hline \hline Linkage property & $\mathrm{SD}^{1}$ \\
\hline Strength of interaction & 1.11 \\
State of knowledge & 1.09 \\
Variability of linkage & 1.01 \\
Spatial scale & 0.87 \\
Temporal scale & 0.62 \\
\hline \hline
\end{tabular}

${ }^{1}$ Values are the mean standard deviation (SD) of responses for a given rating question across all linkages.

\section{Case Study 2: Stressor-Impact Modeling of Chinook Salmon}

The group produced a consensus Chinook salmon life history model containing eight discrete life history stages (Fig. 2). The initial prior model (not shown) involved only six life stages, condensing freshwater rearing and spawning into single stages; however, the group decided that these critical life stages should be disaggregated into finer steps.

Fourteen key stressors were identified as being important in affecting survival through life stages in the conceptual model for Alaskan Chinook salmon (Table 3). Experts had consistent agreement for stressor-life stage ratings (grand mean of standard deviation of responses $=1.03$ ). Standard deviations of ratings also remained consistent for
TABLE 2. Ratio of strength of interaction to state of knowledge for linkages in the zooplankton-herring-whale model. ${ }^{1}$

\begin{tabular}{lc}
\hline \hline Linkage & Ratio \\
\hline acidification-zooplankton & 1.26 \\
upwelling-acidification & 1.19 \\
zooplankton-herring & 1.13 \\
herring-whale & 1.04 \\
upwelling-zooplankton & 1.02 \\
whale-herring & 0.96 \\
zooplankton-whale & 0.91 \\
whale-zooplankton & 0.90 \\
\hline \hline
\end{tabular}

${ }^{1} X-Y$ represents the effect of $X$ on $Y$.

both high- and low-rated stressor-life stage combinations (online Appendix 3).

The stressors rated with the highest strength of impact on the egg to alevin stages were related to siltation and water condition (Fig. 2; online Appendix 3). For the juvenile stages in freshwater, the highest impact stressors were related to predation, food availability, and habitat access, although cold water temperatures were a top stressor for overwinter juvenile rearing. Similarly, food availability, predation, and water temperature were perceived as important stressors on the juvenile ocean rearing stage. Finally, fishing harvest, fishery selectivity, and habitat access were rated as top stressors on the spawning life stages. 


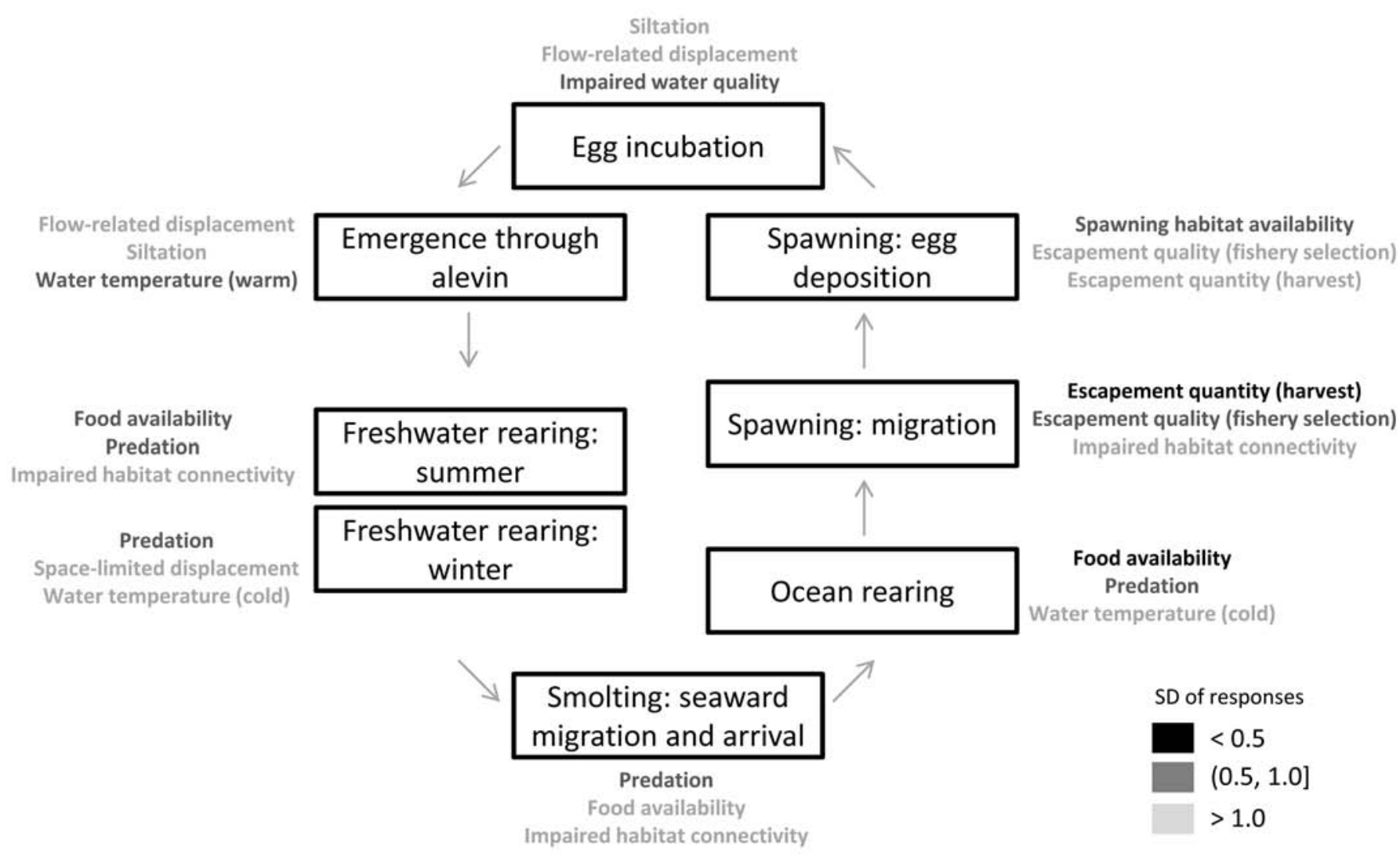

FIG. 2. The consensus Chinook salmon life history model. The three top-rated stressors in terms of "strength of impact on a life stage" are indicated next to each life stage, in descending order from greatest to least impact. Font shading corresponds to the level of agreement on stressor impact ratings as measured by the standard deviation of responses, with darker shading indicating higher agreement (see online Appendix 2).

TABLE 3. Stressors on Chinook salmon life history stages.

\begin{tabular}{ll}
\hline \hline Category & Stressor \\
\hline Environmental & Water temperature (cold) \\
& Water temperature (warm) \\
& Flow-related displacement \\
& Impaired habitat connectivity \\
& Siltation \\
& Impaired water quality \\
& Food availability \\
Biological & Disease \\
& Predation \\
& Spawning habitat availability \\
& Space-limited displacement (competition) \\
Anthropogenic & Escapement quantity (harvest) \\
& Escapement quality and fishery selection \\
& Hatchery-related genetic introgression \\
\hline \hline
\end{tabular}

In general, experts rated few stressors as receiving much research or management attention, with the exception of harvest levels and escapement quantity, which have received considerable research and management effort in the region (Fig. 2; online Appendix 3). Habitat connectivity during freshwater rearing, water temperature during ocean rearing, and disease during spawning migration were rated as receiving intermediate amounts of research and management attention.

From the composite prioritization scores, population genetic effects related to harvest and hatchery introgression were rated as top priority on the egg to alevin stages, as was the role of disease (Table 4; online Appendix 3). Predation and habitat access were consistently high priority for the freshwater life stages. During ocean rearing, food availability was a top priority stressor, as were the effects of hatchery introgression. Finally, during spawning, hatchery introgression, water quality, and stressors related to habitat access were top priorities based upon the composite scoring metric.

\section{DISCUSSION}

Case studies demonstrated that conceptual modeling was an effective tool for synthesizing and presenting information about ecological systems and subsequently prioritizing system components for research or management attention. The zooplankton-herring-whale model identified several important insights among the group of modeling participants. While considerable debate persists about the relative roles of top-down versus bottom-up mediation of forage fish stocks in temperate oceans, the zooplanktonherring-whale modeling effort indicated potential for bottom-up control of Pacific herring stocks in Prince William Sound. Interactions between zooplankton and herring, and between herring and whales, indicated higher strength of 
TABLE 4. Top-ranked stressors based upon prioritization scores for the consensus Chinook salmon model. ${ }^{1}$

\begin{tabular}{|c|c|c|}
\hline Life stage & Rank & Stressor $^{2}$ \\
\hline \multirow[t]{4}{*}{ Egg incubation (11) } & 1 & Hatchery introgression \\
\hline & 2 & Escapement quality \\
\hline & 2 & Impaired water quality \\
\hline & 3 & Escapement quantity \\
\hline \multirow[t]{3}{*}{ Emergence-alevin (9) } & 1 & Hatchery introgression \\
\hline & 2 & Flow-related displacement \\
\hline & 3 & Disease \\
\hline \multirow[t]{3}{*}{ Freshwater rearing: summer (12) } & 1 & Flow-related displacement \\
\hline & 2 & Water temperature (warm) \\
\hline & 3 & Predation \\
\hline \multirow[t]{3}{*}{ Freshwater rearing: winter (13) } & 1 & Predation \\
\hline & 2 & Food availability \\
\hline & 3 & Space-limited displacement \\
\hline \multirow[t]{3}{*}{ Smolting migration/ocean arrival (11) } & 1 & Food availability \\
\hline & 2 & Water temperature (cold) \\
\hline & 3 & Space-limited displacement \\
\hline \multirow[t]{3}{*}{ Ocean rearing (9) } & 1 & Food availability \\
\hline & 2 & Hatchery introgression \\
\hline & 3 & Predation \\
\hline \multirow[t]{3}{*}{ Spawning: migration (12) } & 1 & Hatchery introgression \\
\hline & 2 & Flow-related displacement \\
\hline & 3 & Impaired water quality \\
\hline \multirow[t]{5}{*}{ Spawning: egg deposition (13) } & 1 & Spawning habitat availability \\
\hline & 2 & Hatchery introgression \\
\hline & 3 & Predation \\
\hline & 3 & Space-limited displacement \\
\hline & 3 & Impaired habitat connectivity \\
\hline
\end{tabular}

${ }^{1}$ Results are from 10 respondents, and stressors within each life stage are ranked by impact rating. (See online Appendix 2 for rating questions.) The number of retained stressors affecting life stages is indicated parenthetically.

${ }^{2}$ Stressor prioritization score $=0.33 \times($ impact rating $)+0.33 \times$ (absolute value (knowledge rating -5.0$)$ ) $+0.33 \times$ (absolute value (attention rating -5.0$)$ ). The knowledge and attention ratings were translated in such a way that a high score indicates a low state of knowledge or little research or management attention devoted to a stressor and its impact. High scores therefore indicated high-priority items for future management and research efforts.

relationship moving up the food web (i.e., interactions representing energy flow from lower to higher trophic levels). Similarly, ocean acidification was highlighted as a significant long-term process that may indirectly affect Pacific herring stocks in Prince William Sound by harming their zooplankton prey base; this process was rated as having a relatively strong impact and occurring over basin-wide scales, but with relatively poor state of understanding about the dynamics of ocean acidification and the subsequent impacts on planktonic organisms. While several studies have shown the potential for substantial ecosystem-wide reorganization and trophic transfer impacts associated with ocean acidification (Fabry et al., 2008, 2009; Rossol et al., 2012), much of the research on biological impacts of ocean acidification to date has been focused on laboratory trials (Branch et al., 2013). The zooplankton-herring-whale modeling group's prioritization of potential impacts from ocean acidification on an important forage fish resource in Prince
William Sound emphasizes the need for field studies to examine impacts on specific fish taxa to complement laboratory trials.

Implementation of composite prioritization scores as part of the Chinook salmon conceptual modeling effort at the U.S. Fish and Wildlife Service allowed for management and research strategic planning that simultaneously considered a suite of factors important for the organization's operations planning. This conceptual modeling effort provided information that enables the group to tailor research projects to fill existing gaps in management of Chinook salmon resources in the study region; indeed, top priority stressor-life stage combinations were different from those rated purely on strength of impact (Table 4; Appendix 3). The exercise highlighted the dearth of information about Chinook salmon life history in Alaska, where most of the available management and field budgets are focused on fishery-related monitoring projects necessary to implement subsistence, commercial, and sport fisheries. The process of constructing the Chinook salmon stressor conceptual model and generating prioritization scores was well received at the U.S. Fish and Wildlife Service in Alaska and has since been incorporated into strategic operations planning efforts for other stocks of Pacific salmon under the agency's jurisdiction.

Feedback from conceptual modeling participants involved in the zooplankton-herring-whale and Chinook salmon case studies was generally positive, emphasizing that the process helped assemble groups' understanding of systems by formalizing lists of system components and ultimately producing a visual representation of how system components interact. Many participants were surprised by the amount of organization and synthesis achievable during the one-day conceptual modeling workshops. Furthermore, the conceptual modeling exercises provided a transparent and objective method for prioritizing system components for research or management attention. The steps taken to create a conceptual model, information about modeling participants, system component rating methods, and the raw expert rating data can be made available to stakeholders for critique. Sensitivity analyses can be carried out by testing different rules for reaching consensus about including a system component (e.g., majority- versus threshold-based rules), different consensus scoring metrics (e.g., median versus mean ratings), and different research or management prioritization scores. Such testing provides transparency about the robustness or weakness of modeling conclusions when prioritizing system components for management or research. Finally, prioritization scores can be custom-tailored to address specific objectives in conducting a conceptual modeling exercise. For example, the Chinook salmon case study included a prioritization score that incorporated both state of knowledge and state of management or research efforts currently being devoted to a given model component, highlighting system components that fall within a knowledge and management gap. Addressing these gaps would lead to a strategy of complementing 
extant research and management efforts for Chinook salmon management.

A potentially useful extension to the conceptual modeling approach outlined above is to include ratings for the cost and feasibility of successfully implementing research or management efforts to address a given system component. If available, monetary cost information could be directly incorporated into the conceptual modeling process, for example, by identifying costs for specific research or management projects to address a system component. Alternatively, subjective ratings by modeling participants could be used to provide relative rankings of system components based upon cost or feasibility. By including cost or feasibility considerations, conceptual modeling can support cost-benefit evaluation of alternatives and calculations of value of information in a structured decision analysis framework, facilitating research and management planning in both near- and long-term timeframes (Schmoldt and Peterson, 2000). For example, participants in the Chinook salmon case study rated both habitat connectivity and disease as high-priority stressor-life stage combinations during the spawning freshwater migration (low state of knowledge, low state of management or research attention, and high strength of impact). In general, habitat connectivity restoration efforts such as fish passage barrier removal are costly, and implementing them may require long-term planning for staff and funding (e.g., the State of Washington estimates approximately $\$ 3.9$ million USD per culvert mitigation project within the state; WSDOT, 2014). Alternatively, research on disease dynamics may be more readily addressed given extant funding and staffing levels in the near term. Thus, when faced with limited budgets, decision makers may choose to prioritize lower-cost, disease-related research in the near term, and work towards expensive habitat connectivity projects in long-term planning.

Respondent critique common to both case studies indicated that experts felt constrained by starting with prior models. While prior models are not necessary, we note that the conceptual modeling exercises would likely not have been achievable in one-day workshops without them. Indeed, we found that group discussions began quickly when we presented a starting model, and while prior conceptual models guided the process, groups successfully updated the starting model and reached an agreed-upon consensus model (e.g., see the Chinook salmon strategic planning case study). Conceptual models larger than the case studies presented here can quickly become time-intensive, presenting a practical limit to what can be achieved in a one- or two-day workshop. In such cases, larger systems could be broken into submodels, with smaller groups working in parallel, or analysts could rely more heavily on literature, as opposed to in-person group participation, to inform models (e.g., Radomski and Goeman, 1996; Harwell et al., 2010). The provision of additional time for conceptual model generation without the use of a prior model, when possible, allows participants to become familiar with the modeling process, establish relationships, and identify communication issues, benefiting later stages of the conceptual modeling process, including use of the model for prioritization, communication, or decision making (M.A. Harwell, pers. comm. 2015). In practice, efforts involving multiple stakeholder groups often use a series of modeling workshops to provide sufficient time to develop a conceptual model and familiarize participants with the modeling process (Ogden et al., 2005 and related articles in the special issue of Wetlands, Vol. 25).

We achieved success with quantitative scoring of conceptual model component attributes with a group of relatively well informed and like-skilled participants for the marine and freshwater case studies presented above. We caution, however, against over-interpretation of quantitative metrics, particularly in cases where participants may not have adequate understanding or experience to make informed ratings. In such cases, quantitative metrics may portray false precision, and simpler qualitative ratings approaches, such as a two-category "high" or "low" rating approach, may better reflect participants" abilities to rate model components, while still allowing for the ability to organize and prioritize model components. Indeed, another common modeling extension indicated by respondents during modeling feedback was the inclusion of participant self-ratings to accommodate varying degrees of expertise about system components. As indicated earlier, respondent self-ratings could be used to create weighted averages of system-attribute ratings. The suggestion at least serves as a reminder that the quality of any model reflects the inputs used to construct it, and whenever possible, conceptual modeling participants need to encompass relevant knowledge about the given system to be explored.

Conceptual models provide a transparent way to prioritize research and management objectives among diverse groups of stakeholders and can provide an effective communication tool for informing stakeholders or funders about progress in addressing system components through research or management (e.g., Ogden et al., 2005 and related articles in the special issue of Wetlands, Vol. 25). Changes in system uncertainty over time resulting from management or research efforts can be visualized using conceptual maps, for example, by employing color shades or intensities to represent the state of knowledge about a system component. In an analogous scheme, color or shading-coded conceptual maps can illustrate changes in allocation of management or research resources in response to an identified management or research priority. In effect, conceptual models can provide a visualization of a business plan to help organizations make the best use of their limited resources.

In addition to synthesizing systems understanding, conceptual models present a practical operations tool to address the challenges of implementing cross-disciplinary and cross-organizational management and research efforts to address socioecological systems. Reviews of large systems research and management collaborations have demonstrated that communication of objectives and results among 
collaborators, stakeholders, and funders is critical for success (Alberti et al., 2011; Sievenan et al., 2012). Conceptual models provide a condensed body of information that can be transferred among organizations, facilitating sharing of knowledge and highlighting commonalities and differences in beliefs about a system (e.g., Heemskerk et al., 2003). By their visual nature, they provide succinct representations of complex systems that can be shared with both technical and non-technical stakeholders involved in decision making and management of the modeled system. Formalization of stakeholder priorities through quantitative scores can also provide a unified framework for identifying and addressing conflicting interests in making management decisions about natural resource systems. Once developed, conceptual models can aid decision making and management of complex systems by providing a simulation tool to explore management options and consider future scenarios (i.e., "scenario planning"; e.g., Radomski and Goeman, 1996; Peterson et al., 2003).

\section{ACKNOWLEDGEMENTS}

We thank participants in the 2012 Gulf Watch Alaska conceptual modeling workshop and the 2013 Kenai Fish and Wildlife Service Field Office Chinook Salmon planning workshop (co-led by J. Anderson, USFWS). S. Ulman (AK SeaLife Center) provided valuable project support. K. Holderied (Kasitsna Bay Labs, NOAA) is thanked for help in the genesis of this project and for contributing ideas to structure the modeling process. Project funding was provided through the Exxon Valdez Oil Spill Trustee Council under the Gulf Watch Alaska program and by the U.S. Fish and Wildlife Service Region 7 Fisheries and Ecological Services division. M.A. Harwell, two anonymous reviewers, and Arctic journal staff provided helpful critique that improved an earlier draft of this manuscript. The findings and conclusions in this article are those of the authors and do not necessarily represent the views of the U.S. Fish and Wildlife Service.

\section{APPENDICES}

The following appendices are available in a supplementary file to the online version of this article at:

http://arctic.journalhosting.ucalgary.ca/arctic/index.php/ arctic/rt/SuppFiles/4521/0

APPENDIX 1. Linkage ratings exercise for zooplanktonherring-whale conceptual ecological model.

APPENDIX 2. Chinook salmon conceptual model stressorlife history stage impact ratings exercise.

APPENDIX 3. Chinook salmon stressor-life history stage impact consensus ratings.

\section{REFERENCES}

Alberti, M., Asbjornsen, H., Baker, L.A., Brozovic, N., Drinkwater, L.E., Drzyzga, S.A., Jantz, C.A., et al. 2011. Research on coupled human and natural systems (CHANS): Approach, challenges, and strategies. Bulletin of the Ecological Society of America 92(2):218-228.

http://dx.doi.org/10.1890/0012-9623-92.2.218

Axelrod, R. 1976. Structure of decision: The cognitive maps of political elites. Princeton, New Jersey: Princeton University Press.

Bostrom, A., Fischhoff, B., and Granger Morgan, M. 1992. Characterizing mental models of hazardous processes: A methodology and an application to radon. Journal of Social Issues 48(4):85-100. http://dx.doi.org/10.1111/j.1540-4560.1992.tb01946.x

Botsford, L.W., Castilla, J.C., and Peterson, C.H. 1997. The management of fisheries and marine ecosystems. Science 277(5325):509-515.

http://dx.doi.org/10.1126/science.277.5325.509

Branch, T.A., Hilborn, R., Haynie, A.C., Fay, G., Flynn, L., Griffiths, J., Marshall, K.N., et al. 2006. Fleet dynamics and fishermen behavior: Lessons for fisheries managers. Canadian Journal of Fisheries and Aquatic Sciences 63(7):1647-1668. http://dx.doi.org/10.1139/f06-072

Branch, T.A., DeJoseph, B.M., Ray, L.J., and Wagner, C.A. 2013. Impacts of ocean acidification on marine seafood. Trends in Ecology \& Evolution 28(3):178-186.

http://dx.doi.org/10.1016/j.tree.2012.10.001

Christensen, N.L., Bartuska, A.M., Brown, J.H., Carpenter, S., D’Antonio, C., Francis, R., Franklin, J.F., et al. 1996. The report of the Ecological Society of America Committee on the scientific basis for ecosystem management. Ecological Applications 6(3):665-691. http://dx.doi.org/10.2307/2269460

Conroy, M.J., and Peterson, J.T. 2013. Decision making in natural resource management: A structured, adaptive approach. New York: Wiley-Blackwell.

Cormier, S.M., Smith, M., Norton, S., and Neiheisel, T. 2009. Assessing ecological risk in watersheds: A case study of problem formulation in the Big Darby Creek watershed, Ohio, USA. Environmental Toxicology and Chemistry 19(4):10821096.

http://dx.doi.org/10.1002/etc.5620190439

Estes, J.A., and Duggins, D.O. 1995. Sea otters and kelp forests in Alaska: Generality and variation in a community ecological paradigm. Ecological Monographs 65(1):75-100. http://dx.doi.org/10.2307/2937159

Fabry, V.J., Seibel, B.A., Feely, R.A., and Orr, J.C. 2008. Impacts of ocean acidification on marine fauna and ecosystem processes. ICES Journal of Marine Science 65(3):414-432. http://dx.doi.org/10.1093/icesjms/fsn048

Fabry, V.J., McClintock, J.B., Mathis, J.T., and Grebmeier, J.M. 2009. Ocean acidification at high latitudes: The bellwether. Oceanography 22(4):160-171.

http://dx.doi.org/10.5670/oceanog.2009.105 
Fulton, E.A., Smith, A.D.M., Smith, D.C., and van Putten, I.E. 2011a. Human behaviour: The key source of uncertainty in fisheries management. Fish and Fisheries 12(1):2-17. http://dx.doi.org/10.1111/j.1467-2979.2010.00371.x

Fulton, E.A., Link, J.S., Kaplan, I.C., Savina-Rolland, M., Johnson, P., Ainsworth, C., Horne, P., et al. 2011b. Lessons in modelling and management of marine ecosystems: The Atlantis experience. Fish and Fisheries 12(2):171-188. http://dx.doi.org/10.1111/j.1467-2979.2011.00412.x

Groot, C., Margolis, L., and Clark, W.C., eds. 1995. Physiological ecology of Pacific salmon. Vancouver, British Columbia: UBC Press.

Gross, J.E. 2003. Developing conceptual models for monitoring programs. Fort Collins, Colorado: NPS Inventory and Monitoring Program.

https://science.nature.nps.gov/im/monitor/docs/Conceptual_ Modelling.pdf

Harwell, M.A., Long, J.F., Bartuska, A.M., Gentile, J.H., Harwell, C.C., Myers, V., and Ogden, J.C. 1996. Ecosystem management to achieve ecological sustainability: The case of South Florida. Environmental Management 20(4):497-521. http://dx.doi.org/10.1007/BF01474652

Harwell, M.A., Gentile, J.H., Cummins, K.W., Highsmith, R.C., Hilborn, R., McRoy, C.P., Parrish, J., and Weingartner, T. 2010. A conceptual model of natural and anthropogenic drivers and their influence on the Prince William Sound, Alaska, ecosystem. Human and Ecological Risk Assessment 16(4):672-726.

http://dx.doi.org/10.1080/10807039.2010.501011

Hastie, R., and Kameda, T. 2005. The robust beauty of majority rules in group decisions. Psychological Review 112(2):494508. http://dx.doi.org/10.1037/0033-295x.112.2.494

Heemserk, M., Wilson, K., and Pavao-Zuckerman, M. 2003. Conceptual models as tools for communication across disciplines. Conservation Ecology 7(3): 8. http://www.consecol.org/vol7/iss3/art8/

Hill, G.W. 1982. Group versus individual performance: Are $N+$ 1 heads better than one? Psychological Bulletin 91(3):517-539. http://dx.doi.org/10.1037/0033-2909.91.3.517

Howard, R.A. 1989. Knowledge maps. Management Science 35(8):903-922.

http://dx.doi.org/10.1287/mnsc.35.8.903

Kerr, N.L., MacCoun, R.J., and Kramer, G.P. 1996. Bias in judgment: Comparing individuals and groups. Psychological Review 103(4):687-719. http://dx.doi.org/10.1037//0033-295x.103.4.687

King, E.G., and Hobbs, R.J. 2006. Identifying linkages among conceptual models of ecosystem degradation and restoration: Towards an integrative framework. Restoration Ecology 14(3):369-378. http://dx.doi.org/10.1111/j.1526-100X.2006.00145.x

Kosko, B. 1986. Fuzzy cognitive maps. International Journal of Man-Machine Studies 24(1):65-75. http://dx.doi.org/10.1016/S0020-7373(86)80040-2
Maier, N.R. 1967. Assets and liabilities in group problem solving: The need for an integrative function. Psychological Review 74(4):239-249. http://dx.doi.org/10.1037/h0024737

Marcot, B.G., Holthausen, R.S., Raphael, M.G., Rowland, M.M., and Wisdom, M.J. 2001. Using Bayesian belief networks to evaluate fish and wildlife population viability under land management alternatives from an environmental impact statement. Forest Ecology and Management 153(1-3):29-42. http://dx.doi.org/10.1016/S0378-1127(01)00452-2

Marcot, B.G., Steventon, J.D., Sutherland, G.D., and McCann, R.K. 2006. Guidelines for developing and updating Bayesian belief networks applied to ecological modeling and conservation. Canadian Journal of Forest Research 36(12):3063-3074.

http://dx.doi.org/10.1139/x06-135

McDaniels, T., Wilmot, S., Healey, M., and Hinch, S. 2010. Vulnerability of Fraser River sockeye salmon to climate change: A life cycle perspective using expert judgments. Journal of Environmental Management 91(12):2771-2780. http://dx.doi.org/10.1016/j.jenvman.2010.08.004

MEA (Millennium Ecosystem Assessment). 2005. Ecosystems and human well-being: Synthesis. Washington, D.C.: Island Press.

Novak, J.D., and Cañas, A.J. 2006. The origins of the concept mapping tool and the continuing evolution of the tool. Information Visualization 5(3):175-184. http://dx.doi.org/10.1057/palgrave.ivs.9500126

Ogden, J.C., Davis, S.M., Jacobs, K.J., Barnes, T., and Fling, H.E. 2005. The use of conceptual ecological models to guide ecosystem restoration in south Florida. Wetlands 25(4):795809. http://dx.doi.org/10.1672/0277-5212(2005)025[0795:TUOCEM ]2.0.CO;2

Özesmi, U., and Özesmi, S.L. 2004. Ecological models based on people's knowledge: A multi-step fuzzy cognitive mapping approach. Ecological Modelling 176(1-2):43-64. http://dx.doi.org/10.1016/j.ecolmodel.2003.10.027

Pauly, D., Christensen, V., and Walters, C. 2000. Ecopath, Ecosim, and Ecospace as tools for evaluating ecosystem impact of fisheries. ICES Journal of Marine Science 57(3):697-706. http://dx.doi.org/10.1006/jmsc.2000.0726

Peterson, G.D., Cumming, G.C., and Carpenter, S.R. 2003. Scenario planning: A tool for conservation in an uncertain world. Conservation Biology 17(2):358-366. http://dx.doi.org/10.1046/j.1523-1739.2003.01491.x

Radomski, P.J., and Goeman, T.J. 1996. Decision making and modeling in freshwater sport-fisheries management. Fisheries 21(12):14-21.

http://dx.doi.org/10.1577/1548-8446(1996)021<0014:DMAMI $\mathrm{F}>2.0 . \mathrm{CO} ; 2$

R Development Core Team. 2013. R: A language and environment for statistical computing. Vienna: R Foundation for Statistical Computing.

Robinson, S. 2008a. Conceptual modelling for simulation Part I: Definition and requirements. Journal of the Operational Research Society 59:278-290. http://dx.doi.org/10.1057/palgrave.jors.2602368 
_ _ 2008b. Conceptual modelling for simulation Part II: A framework for conceptual modelling. Journal of the Operational Research Society 59:291-304.

http://dx.doi.org/10.1057/palgrave.jors.2602369

Robinson, S., Brooks, R., Kotiadis, K., and van der Zee, D.-J., eds. 2010. Conceptual modeling for discrete-event simulation. Boca Raton, Florida: CRC Press. http://dx.doi.org/10.1201/9781439810385

Rose, K.A., Allen, J.I., Artioli, Y., Barange, M., Blackford, J., Carlotti, F., Cropp, R., et al. 2010. End-to-end models for the analysis of marine ecosystems: Challenges, issues, and next steps. Marine and Coastal Fisheries: Dynamics, Management, and Ecosystem Science 2(1):115-130. http://dx.doi.org/10.1577/C09-059.1

Rossoll, D., Bermúdez, R., Hauss, H., Schulz, K.G., Riebesell, U., Sommer, U., and Winder, M. 2012. Ocean acidificationinduced food quality deterioration constrains trophic transfer. PLoS ONE 7: e34737. http://dx.doi.org/10.1371/journal.pone.0034737

Schmoldt, D.L., and Peterson, D.L. 2000. Analytical group decision making in natural resources: Methodology and application. Forest Science 46(1):62-75.

Sievanen, L., Campbell, L.M., and Leslie, H.M. 2012. Challenges to interdisciplinary research in ecosystem-based management. Conservation Biology 26(2):315-323. http://dx.doi.org/10.1111/j.1523-1739.2011.01808.x

Simenstad, C., Logsdon, M., Fresh, K., Shipman, H., Dethier, M., and Newton, J. 2006. Conceptual model for assessing restoration of Puget Sound nearshore ecosystems. Puget Sound Nearshore Partnership Technical Report 2006-03. Seattle: Washington Sea Grant Program.

Spence, B.C., Lomnicky, G.A., Hughes, R.M., and Novitzki, R.P. 1996. An ecosystem approach to salmonid conservation. Technical Report 21TR-4501-96-6057. Corvallis, Oregon: Management Technology Environmental Research Services Corp.
Suter, G.W., II. 1996. Guide for developing conceptual models for ecological risk assessments. Report ES/ER/TM-186. Springfield, Virginia: National Technical Information Service, U.S. Department of Commerce.

U.S. EPA (U.S. Environmental Protection Agency). 1992. Framework for ecological risk assessment. EPA/630/R-92/001. Washington, D.C.: U.S. EPA.

Uusitalo, L. 2007. Advantages and challenges of Bayesian networks in environmental modelling. Ecological Modelling 203(3-4):312-318.

http://dx.doi.org/10.1016/j.ecolmodel.2006.11.033

Wittmann, M.E., Cooke, R.M., Rothlisberger, J.D., Rutherford, E.S., Zhang, H., Mason, D.M., and Lodge, D.M. 2015. Use of structured expert judgment to forecast invasions by bighead and silver carp in Lake Erie. Conservation Biology 29(1):187197.

http://dx.doi.org/10.1111/cobi.12369

WSDOT (Washington State Department of Transportation). 2014. Accelerating fish barrier correction: New requirements for WSDOT culverts. Fish Passage Informational Pamphlet December 2014. Olympia: Washington State Department of State.

Zaksek, M., and Arvai, J.L. 2004. Toward improved communication about wildland fire: Mental models research to identify information needs for natural resource management. Risk Analysis 24(6):1503-1514. http://dx.doi.org/10.1111/j.0272-4332.2004.00545.x

Zorrilla, P., Carmona, G., De la Hera, Á., Varela-Ortega, C., Martínez-Santos, P., Bromley, J., and Henriksen, H.J. 2010. Evaluation of Bayesian networks in participatory water resources management, Upper Guadiana Basin, Spain. Ecology and Society 15(3): 12. http://www.ecologyandsociety.org/vol15/iss3/art12/ 